Supporting Information

\title{
Liquid crystal compound anti-ice surface
}

Zeqing Wang, Yuehua Cong, Baoyan Zhang*

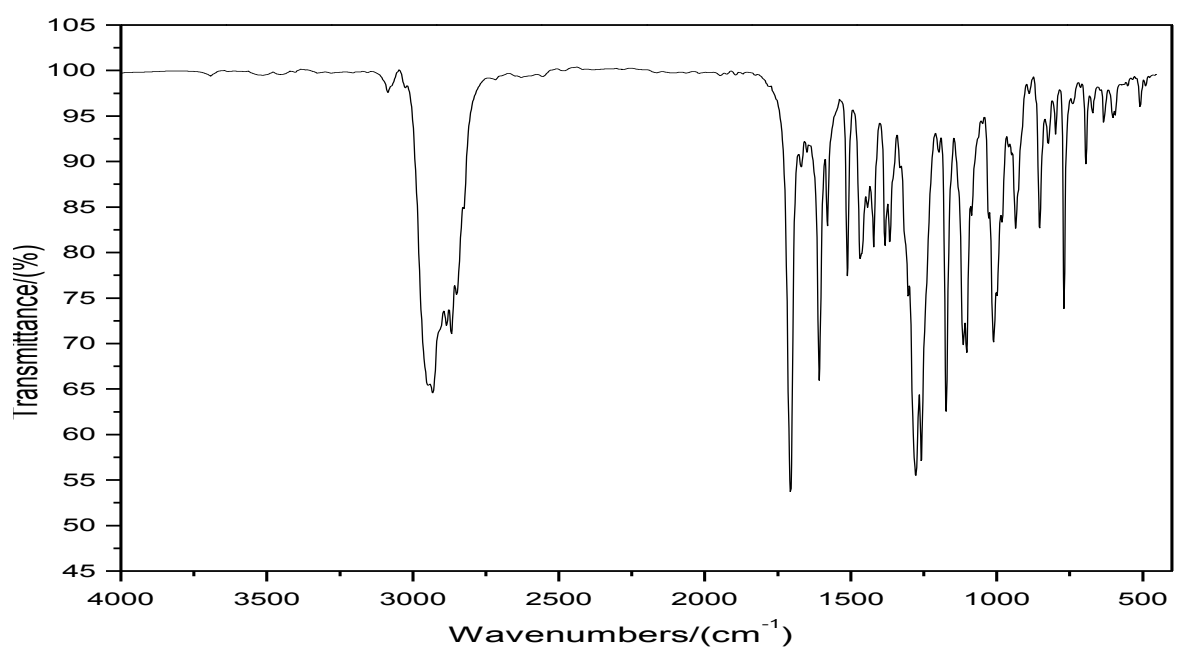

Figure S1. FT-IR spectrogram of $\mathrm{M}_{1}$

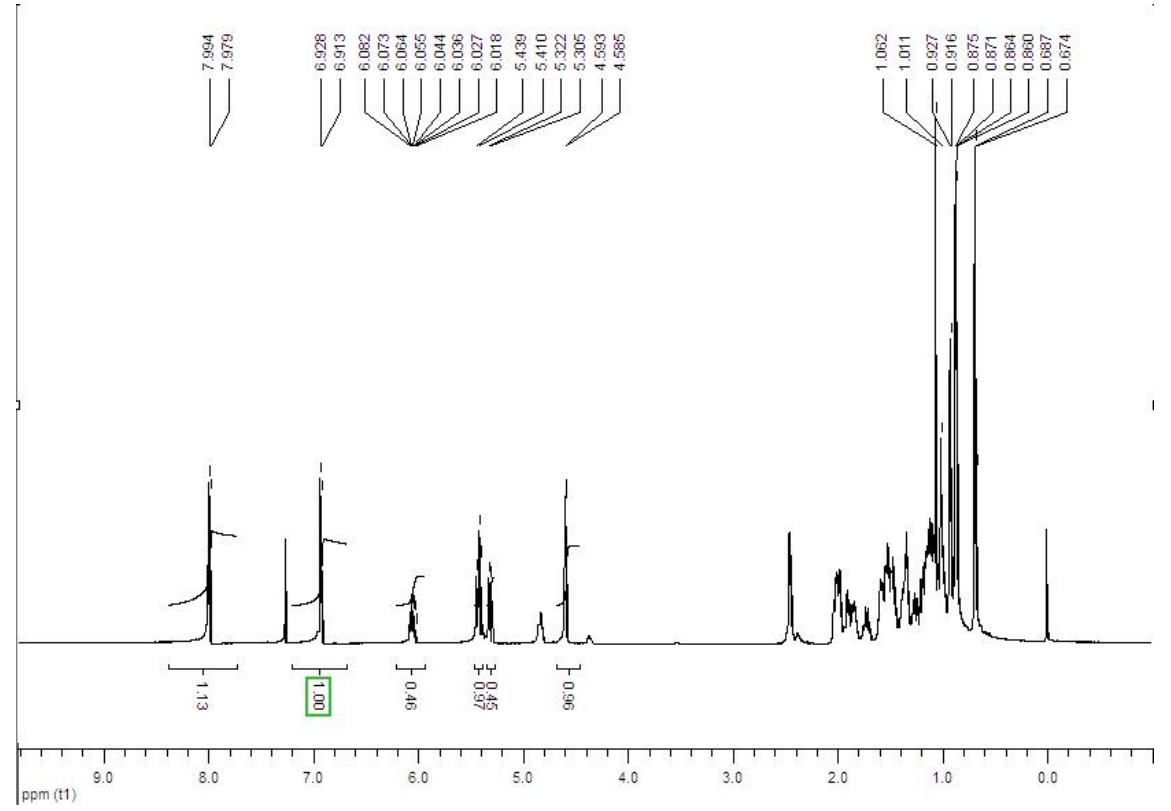

Figure S2. ${ }^{1} \mathrm{H}$ NMR spectrum of liquid crystal compound $\left(600 \mathrm{MHz}, \mathrm{CDCl}_{3}\right)$ 


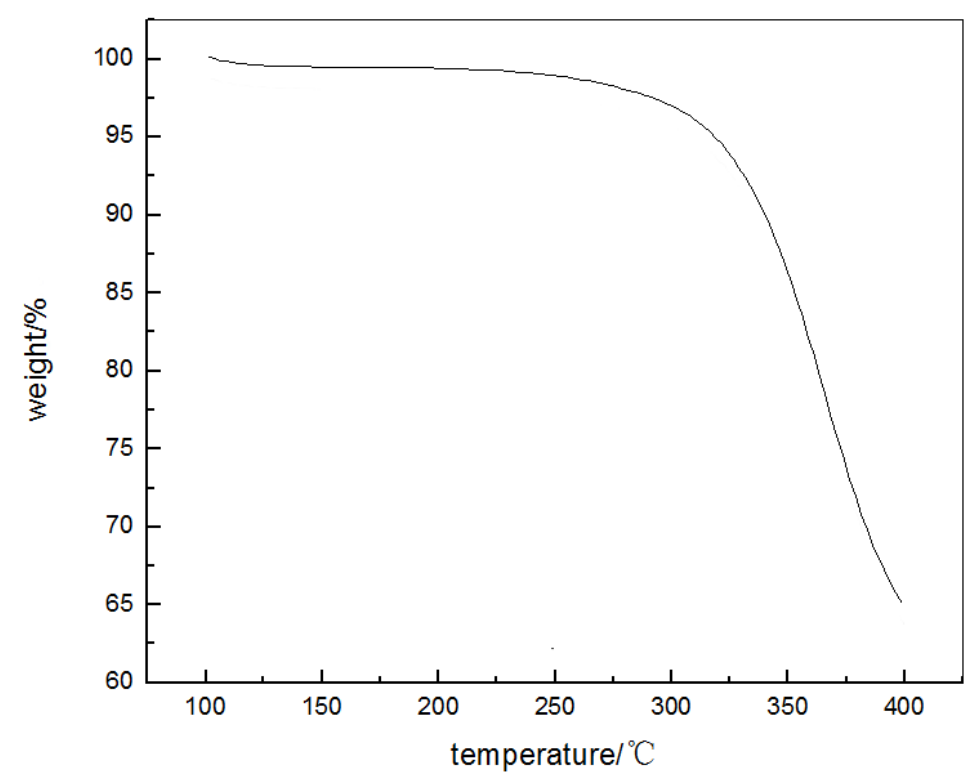

Figure S3 TG curve of M1

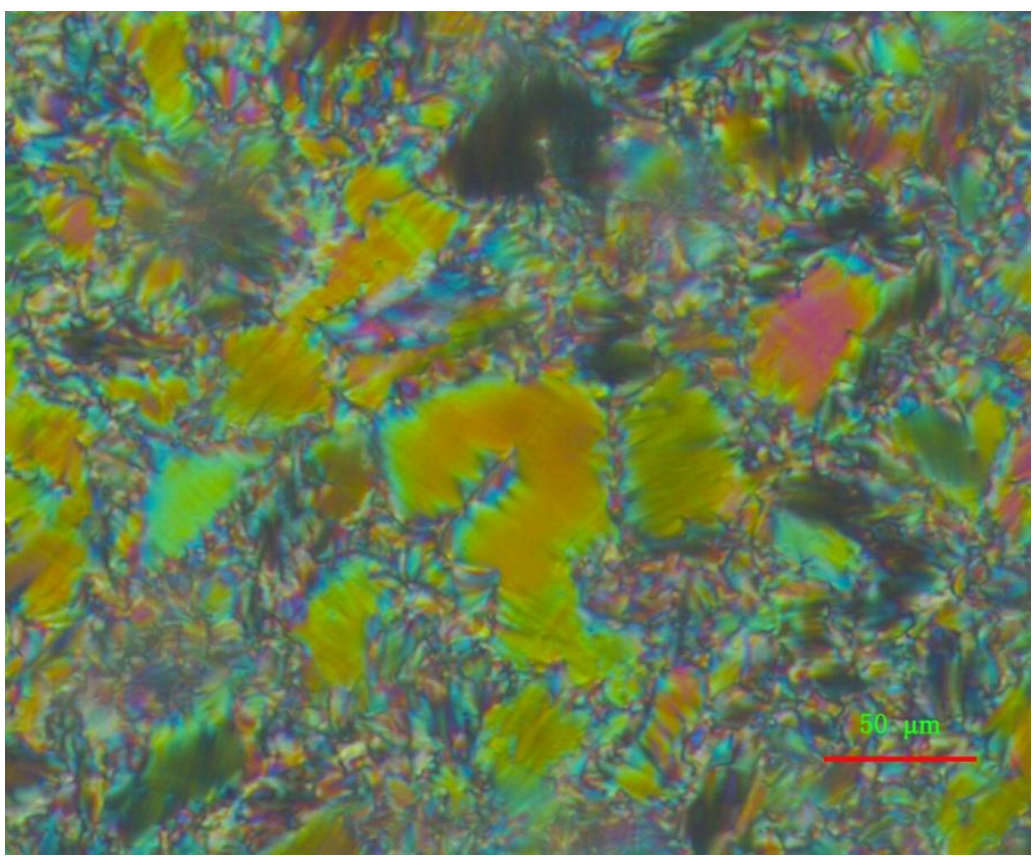

Figure S4 POM photo of $\mathrm{M} 1$ at $-30^{\circ} \mathrm{C}$ 
Table $\mathrm{S} 1$ the results of $\mathrm{M} 1\left(\mathrm{C}_{38} \mathrm{H}_{56} \mathrm{O}_{3}\right)$ elemental analyses

\begin{tabular}{|l|l|l|}
\hline Value & $\mathrm{C} / \%$ & $\mathrm{H} / \%$ \\
\hline Calculated Value & 81.38 & 10.09 \\
\hline Measured Value & 81.30 & 9.94 \\
\hline
\end{tabular}

